\title{
MicroRNA-197-3p acts as a prognostic marker and inhibits cell invasion in hepatocellular carcinoma
}

\author{
JUN-SHENG NI ${ }^{1-3^{*}}$, HAO ZHENG ${ }^{1-3^{*}}$, ZHI-PING HUANG ${ }^{1-4^{*}}$, YONG-GANG HONG ${ }^{5 *}$, YANG-LIU OU ${ }^{5^{*}}$, \\ YUAN-PING TAO ${ }^{1-3}$, MENG-CHAO WANG ${ }^{1-3}$, ZHEN-GUANG WANG ${ }^{1-3}$, YUAN YANG ${ }^{1-3}$ and WEI-PING ZHOU ${ }^{1-3}$ \\ ${ }^{1}$ Third Department of Hepatic Surgery, Eastern Hepatobiliary Surgery Hospital, Second Military Medical University; \\ ${ }^{2}$ Key Laboratory of Signalling Regulation and Targeting Therapy of Liver Cancer (SMMU), Ministry of Education; \\ ${ }^{3}$ Shanghai Key Laboratory of Hepatobiliary Tumor Biology (EHBH), Shanghai 200438; ${ }^{4}$ Department of Hepatobiliary Surgery, \\ General Hospital of Guangzhou Military Command of PLA, Guangzhou, Guangdong 510010; \\ ${ }^{5}$ Department of Colorectal Surgery, Changhai Hospital, Second Military Medical University, Shanghai 200433, P.R. China
}

Received March 22, 2018; Accepted November 16, 2018

DOI: $10.3892 / \mathrm{ol} .2018 .9848$

\begin{abstract}
MicroRNAs (miRNAs) serve an important regulatory role in carcinogenesis and cancer progression. Aberrant expression of miR-197-3p has been reported in various human malignancies. However, the role of miR-197-3p in the progression and prognosis of hepatocellular carcinoma (HCC) remains unknown. The present study demonstrated that miR-197-3p was downregulated in HCC tissues and that the low level of miR-197-3p expression in HCC tumours correlated with aggressive clinicopathological characteristics; thus, miR-197-3p may serve as a predictor for poor prognosis in patients with HCC. Additionally, miR-197-3p markedly inhibited the metastasis of HCC cells in vitro and in vivo. Bioinformatics analysis further identified zinc finger protein interacted with $\mathrm{K}$ protein 1 (ZIK1) as a novel target of miR-197-3p in HCC cells. These findings suggest that miR-197-3p may regulate the survival of HCC cells, partially through the downregulation of ZIK1. Therefore, the miR-197-3p/ZIK1 axis may serve as a novel therapeutic target in patients with HCC.
\end{abstract}

Correspondence to: Professor Wei-Ping Zhou or Professor Yuan Yang, Third Department of Hepatic Surgery, Eastern Hepatobiliary Surgery Hospital, Second Military Medical University, 225 Changhai Road, Shanghai 200438, P.R. China

E-mail: ehphwp@126.com

E-mail: yy@smmu.edu.cn

*Contributed equally

Abbreviations: RFS, relapse-free survival; OS, overall survival; BCLC, Barcelona Clinic Liver Cancer; EMT, epithelial mesenchymal transition; HCC, hepatocellular carcinoma; ZIK1, zinc finger protein interacting with $\mathrm{K}$ protein 1 ; TNM, tumour node metastasis; AFP, alpha-fetoprotein

Key words: microRNA-197-3p, ZIK1, HCC, biomarker, cell invasion

\section{Introduction}

Hepatocellular carcinoma (HCC) is the third most common cause of cancer-associated mortality worldwide, and the highest numbers of HCC cases have been detected in Asia and Africa $(1,2)$. The long-term prognosis of HCC remains unsatisfactory, as indicated by a low overall survival rate of $22-35 \%$ over the last 10 years (3). Since hepatocarcinogenesis involves numerous oncogenes and tumour suppressor genes (4), the molecular carcinogenic mechanisms and the pathogenic biology of HCC have become an issue of great interest $(5,6)$.

MicroRNAs (miRNAs), highly conserved small non-coding RNAs of 19-25 nucleotides, are known to regulate numerous protein-coding genes $(7,8)$. By binding directly to the 3 ' untranslated regions ( $3^{\prime}$ UTR) of target mRNAs, miRNAs may cause posttranscriptional repression of protein synthesis, leading to deadenylation and subsequent mRNA degradation and/or translational inhibition $(9,10)$. A number of miRNAs have been implicated in various cellular processes including apoptosis, cell proliferation, differentiation, stem cell renewal, stress responses and metabolism (11-15). Their marked impact on the regulation of carcinogenesis and tumour suppression indicates that the aberration and regulation of the miRNA biogenesis pathway may contribute to human diseases, including cancer $(8,16,17)$.

In a previous study it was identified that the expression of the miR-197-3p was markedly decreased in HCC compared with the corresponding adjacent non-tumour samples. Additionally, previous studies indicate that miR-197-3p is of great interest in cancer therapy due to its association with various malignancies, including bladder (18) and thyroid cancer (19). The present study demonstrated that low miR-197-3p expression in HCC tissues correlated with poor patient prognosis; thus the focus of the study centred on the roles and corresponding mechanisms of miR-197-3p in the progression of HCC.

\section{Materials and methods}

Cell lines and culture. Human hepatocellular carcinoma cell lines (Huh7, HCC-LM3, and Hep3B) and a hepatocellular cell line (THLE-3) were purchased from the Cell Resource 
Centre of the Shanghai Institute of Life Sciences (Shanghai, China). All cell lines were cultured in Dulbecco's modified Eagle's medium (DMEM; HyClone; GE Healthcare Life Sciences, Logan, UT, USA) supplemented with $10 \%$ foetal bovine serum (FBS) and $1 \%$ penicillin/streptomycin (Thermo Fisher Scientific, Inc., Waltham, MA, USA). All cells were maintained at $37^{\circ} \mathrm{C}$ in a humidified atmosphere, at $5 \% \mathrm{CO}_{2}$.

Patients, tumour tissues and serum sample. A total of 197 pairs of snap-frozen HCC and peritumoural tissues were obtained from the Eastern Hepatobiliary Surgery Hospital (Shanghai, China) from 19 females and 178 males (age range, 35-83 years) between January 2010 and October 2014. The tissues were used for reverse transcription-quantitative polymerase chain reaction (RT-qPCR) analysis. Clinical tissue samples were verified as tumour or non-tumour through a histopathological examination and the Edmondson grading system (20). Micrometastases were defined as tumours adjacent to the border of the primary tumour, as observed using a microscope. Tumour staging was defined according to the sixth edition of the tumour, node, metastasis (TNM) classification system (21) published by the International Union Against Cancer. The tissue samples were stored at $-80^{\circ} \mathrm{C}$ until further use. Tumour differentiation was defined according to the $\mathrm{R}$ and Barcelona Clinic Liver Cancer (BCLC) staging systems (22). The study was approved by the Institutional Review Board of the Eastern Hepatobiliary Surgery Hospital. All patients gave written informed consent to participate in the study. The data were anonymized. All clinical specimens were approved by the Clinical Research Ethics Committee of Eastern Hepatobiliary Surgery Hospital.

$R N A$ extraction and $R T-q P C R$. Total RNA from tissues or cells was extracted using the miRNeasy Mini kit (Qiagen, Inc., Valencia, CA, USA) according to the manufacturer's protocol. mRNA and miRNA were reverse-transcribed from total RNA using the Revert Aid First Strand cDNA Synthesis kit (Thermo Fisher Scientific, Inc.), according to the manufacturer's protocol. cDNA was amplified and quantified on a CFX96 system (Bio-Rad Laboratories, Inc., Hercules, CA, USA) using iQ SYBR Green (Bio-Rad Laboratories, Inc.). U6 or GAPDH were used as endogenous controls. Primers for miR-197-3p expression analysis were as follows: miR-197-3p forward, 5'-CACCACCTTCTCCACCCA-3', and reverse, 5'-GGGACTGGACTTGGAGTC-3'; U6 forward, 5'-CTCGCT TCGGCAGCACA-3', and reverse, 5'-AACGCTTCACGA ATTTGCGT-3'. Primers for epithelial mesenchymal transition (EMT) analysis were as follows: E-cadherin forward, 5'-TACACTGCCCAGGAGCCAGA-3', and reverse, 5'-TGG CACCAGTGTCCGGATTA-3'; N-cadherin forward, 5'-TCA GGCGTCTGTAGAGGCTT-3', and reverse, 5'-ATGCACATC CTTCGATAAGACTG-3'; Vimentin forward, 5'-GACGCC ATCAACACCGAGTT-3', and reverse, 5'-CTTTGTCGTTGG TTAGCTGGT-3'; GAPDH forward, 5'-TGTGGGCATCAA TGGATTTGG-3', and reverse, 5'-ACACCATGTATTCCG GGTCAAT-3'. Relative fold expressions were calculated via the comparative quantification cycle $\left(2^{-\Delta \Delta \mathrm{Cq}}\right)$ method (23). Mature miR-197-3p expression was detected using a TaqMan miRNA assay kit (Thermo Fisher Scientific, Inc.) according to the manufacturer's protocol. The RNU6B gene was used as a normalization control. All experiments were performed three times in duplicate. The GAPDH gene was used as an internal control. qPCR was conducted using the following conditions: 30 cycles consisting of denaturation at $94^{\circ} \mathrm{C}$ for $30 \mathrm{sec}$, annealing at $56^{\circ} \mathrm{C}\left(58^{\circ} \mathrm{C}\right.$ for GAPDH) for $30 \mathrm{sec}$, and extension at $72^{\circ} \mathrm{C}$ for $30 \mathrm{sec}$.

Wound healing migration assay. Wound healing migration assays were performed as described previously (24). Briefly, $1 \times 10^{5}$ cells were plated in each well of a 6 -well plate. Once attached, cells were scraped to form a wound in the middle of the plate, and the medium was replaced with serum-free medium. Cells were incubated for $36 \mathrm{~h}$ in a humidified atmosphere containing $5 \% \mathrm{CO}_{2}$ at $37^{\circ} \mathrm{C}$, prior to the measurement of migration across the wound line.

Cellular migration and invasion assays. Cellular migration and invasion were assessed using Transwell chambers with a pore size of $8 \mu \mathrm{m}$ (Corning Inc., Corning, NY, USA). Following transfection for $48 \mathrm{~h}, 5 \times 10^{4}$ transfected cells in $300 \mu 1$ medium without FBS were seeded into the upper chamber, while $500 \mu$ l medium supplemented with $20 \%$ FBS was placed into the lower chamber. For the Matrigel invasion assay, the Transwell chamber was coated with Matrigel (BD Biosciences, San Jose, CA, USA). A total of $5 \times 10^{4}$ transfected cells in $300 \mu \mathrm{l}$ medium without FBS were seeded into the upper chamber of the Transwell, while $500 \mu 1$ medium supplemented with $20 \%$ FBS was placed into the lower chamber. Cells were incubated at $37^{\circ} \mathrm{C}$ for a further $24 \mathrm{~h}$ for the migration assay and $48 \mathrm{~h}$ for the invasion assay. In the two assays, the cells were fixed with $100 \%$ methanol for 5 min (Beyotime Institute of Biotechnology, Haimen, China) and stained with $0.5 \%$ crystal violet (Beyotime Institute of Biotechnology) for $5 \mathrm{~min}$. Subsequently, cells remaining on the upper surface of the membranes were removed carefully using cotton swabs. The migrated and invaded cells were then counted in five randomly selected fields with an inverted microscope (magnification, x200). Each experiment was repeated three times.

Synthetic RNA oligonucleotides and transient transfection. The predicted binding sites between miR-197-3p and zinc finger protein interacted with K protein 1 (ZIK1) were obtained using TargetScan Human online software 7.1 (http://www. targetscan.org/vert_71/). miRNA inhibitors, mimics and an miRNA negative control (NC) were synthesized by Shanghai GenePharma Co., Ltd. (Shanghai, China). The 5'-3' sequences of the three miRNAs were as follows: Mimics, CGGGUAGAG AGGGCAGUGGGAGG and UUCACCACCUUCUCCACC CAGC; inhibitor, AAGUGGUGGAAGAGGUGGGUCG; and NC, CAGUACUUUUGUGUAGUACAA. ZIK1 overexpression vectors and the NC vector were obtained from Shanghai GeneChem Co., Ltd. Cells were seeded at $1-1.5 \times 10^{5} /$ well in a 6-well plate, and transiently transfected with miRNAs $\left(5 \mu \mathrm{g} /\right.$ well) using JetPrime ${ }^{\circledR}$ (Polyplus-transfection SA, Illkirch, France), according to the manufacturer's protocol. The cells were collected for analysis $48 \mathrm{~h}$ post-transfection.

Cell proliferation assay. Cell proliferation was measured using a Cell Counting Kit-8 (CCK-8) assay (Sangon Biotech, Co., Ltd., Shanghai, China). A total of $48 \mathrm{~h}$ post-transfection, 
$3 \times 10^{3}$ cells/well were seeded into a 96 -well plate. The CCK-8 reagent was added $72 \mathrm{~h}$ post-seeding, and optical density was measured using a microplate reader at $450 \mathrm{~nm}$.

Western blotting analysis. Cells were lysed with ice-cold lysis buffer supplemented with protease inhibitor cocktail (Pierce; Thermo Fisher Scientific, Inc.). Total protein concentration was determined using the Enhanced BCA Protein Assay kit (Beyotime Institute of Biotechnology). Protein samples $(20 \mu \mathrm{g})$ were separated on a $10 \%$ SDS-PAGE gel and then transferred to a polyvinylidene fluoride membrane (Roche Diagnostics $\mathrm{GmbH}$, Mannheim, Germany). Following blocking with 5\% skimmed milk at room temperature for $2 \mathrm{~h}$, the membranes were incubated overnight at $4^{\circ} \mathrm{C}$ with rabbit anti-human ZIK1 monoclonal primary antibody $(1: 1,000$; Abcam, Cambridge, UK; cat. no. 107918) and mouse anti-human $\beta$-actin monoclonal primary antibody (1:1,000; Abcam; cat. no. 8226) primary antibodies. Subsequently, the membranes were incubated with goat anti-mouse horseradish peroxidase-conjugated secondary antibody (1:3,000; Abcam; cat. no. ab6789) for $1 \mathrm{~h}$ at room temperature. The membranes were visualized with Super Signal West Pico Chemiluminescent Substrate kit (Pierce; Thermo Fisher Scientific, Inc.). $\beta$-actin was used as a loading control. The Lab Works Image Acquisition and Analysis Software (version 7.0; UVP, LLC, Phoenix, AZ, USA) was used to quantify the band intensities.

Luciferase activity assay. The 3' UTR of ZIK1 was amplified and cloned downstream of the pGL3/Luciferase (Luc) vector (Shanghai GenePharma Co., Ltd.). The mutant 3' UTR of ZIK1 was amplified using the pGL3/Luc-ZIK1 3' UTR as the template and was cloned downstream of the pGL3/Luc vector. For the luciferase reporter assay, either $100 \mathrm{nM}$ of miR-197-3p mimic or control and $2 \mu \mathrm{g}$ pGL3/Luc-ZIK1 3' UTR or the mutant 3 ' UTR, in addition to the controls, were co-transfected into HCCLM 3 cells at $70 \%$ confluence using Lipofectamine ${ }^{\circledR} 2000$ reagent (Thermo Fisher Scientific, Inc.), according to the manufacturer's protocol. At $48 \mathrm{~h}$ post-transfection, the cells were lysed using radioimmunoprecipitation assay buffer (cat. no. P0013C; Beyotime Institute of Biotechnology, China) according to the manufacturer's protocol. Luciferase intensity was measured using an F-4500 Fluorescence Spectrophotometer (Hitachi, Ltd., Tokyo, Japan) and normalized to that of Renilla luciferase, according to the manufacturer's protocol.

Cell proliferation (MTT) assay. HCCLM3 cells transfected with miR-197-3p mimics or control and with the miR-197-3p inhibitor or control were plated into 96 -well plates at a density of $5 \times 10^{4}$ cells/well, under $5 \% \mathrm{CO}_{2}$ at $37^{\circ} \mathrm{C}$ for $48 \mathrm{~h}$. Following incubation for 24,48 or $72 \mathrm{~h}$, the culture plates were incubated with $20 \mu \mathrm{l}$ of MTT/well in $100 \mu \mathrm{l}$ medium at a final concentration of $5 \mathrm{mg} / \mathrm{ml}$ for a further $4 \mathrm{~h}$. The culture plates were centrifuged at $2,000 \mathrm{x} g$ for $5 \mathrm{~min}$ at room temperature. The supernatant was carefully removed, and $100 \mu \mathrm{l}$ dimethyl sulfoxide was added to each well to end the reaction. Blue-violet formazan particles were dissolved for $\sim 10 \mathrm{~min}$ in the dark at $25^{\circ} \mathrm{C}$. The absorbance at $570 \mathrm{~nm}$ was detected using a Quant Universal microplate spectrophotometer (BioTek Instruments, Inc., Winooski, VT, USA). The experiment was repeated three times.
Statistical analysis. All values are presented as the mean \pm standard deviation. Significant differences were determined using GraphPad 5.0 (GraphPad Software, Inc., La Jolla, CA, USA). The difference between the HCC tissues and their corresponding adjacent non-tumour samples was analysed for statistical significance using the paired Student's t-test. Student's t-test was used to determine significant differences between two groups. One-way analysis of variance (ANOVA) was used to determine significant differences between multiple testing. Student-Newman-Keuls test was used as a post hoc test following ANOVA. The $\chi^{2}$ test was used to analyse the association between miR-197-3p expression and clinicopathological characteristics. Survival curves were plotted using the Kaplan-Meier method and were compared via the log-rank test. $\mathrm{P}<0.05$ was considered to indicate a statistically significant difference. To collect dependent variables, multivariate regression analysis was conducted using the significant variables identified in the univariate regression analysis. All experiments were repeated three times.

\section{Results}

Expression of miR-197-3p is markedly downregulated in $H C C$. To investigate the expression and clinical significance of miR-197-3p in HCC, the expression of miR-197-3p in HCC cell lines was examined. Decreased miR-197-3p expression was observed in the HCC cells, compared with the normal liver cells (Fig. 1A). The expression of miR-197-3p was detected in a total of 197 paired primary HCC tissues and their corresponding adjacent non-tumour samples. RT-qPCR indicated that the average expression level of miR-197-3p was significantly lower in the cancerous tissues compared with that in the adjacent non-cancerous tissues (Fig. 1B; P<0.001). Moreover, the miR-197-3p expression declined in HCC patients with larger tumours $(>5 \mathrm{~cm}$ ), a higher $\alpha$-fetoprotein (AFP) serum level $(>20 \mathrm{ng} / \mathrm{ml})$, vascular invasion and early recurrence (Fig. 1C-F).

Association between miR-197-3p expression and clinicopathological characteristics. To evaluate the correlations between miR-197-3p and the selected clinicopathological variables, the cohort of 197 patients were divided into subgroups with low and high miR-197-3p expression. The median value of miR-197-3p expression in all 197 cases was selected as the cut-off value. Consistent with the criteria above, the correlation of miR-197-3p expression with clinicopathological characteristics and the prognosis of HCC were analysed. As presented in Table I, the lo expression group was associated with higher AFP levels $(\geq 20 \mu \mathrm{g} / 1 ; \mathrm{P}<0.001)$, larger tumour size $(\geq 5 \mathrm{~cm}$; $\mathrm{P}=0.012)$, multiple tumours $(\mathrm{n} \geq 2 ; \mathrm{P}<0.001)$, absence of capsule $(\mathrm{P}<0.001)$ and vascular invasion $(\mathrm{P}=0.013)$.

Association between miR-197-3p expression and HCC prognosis. The association between miR-197-3p expression and the prognosis of patients with HCC following hepatectomy was further analysed. It was determined that the group with low miR-197-3p expression exhibited significantly poorer relapse-free survival (RFS) $(\mathrm{P}<0.001$; Fig. 2A) and poorer overall survival $(\mathrm{OS})(\mathrm{P}<0.001$; Fig. $2 \mathrm{~B})$. Previous studies indicated that AFP-negative patients (AFP serum 
Table I. Clinical characteristics of 197 patients with hepatocellular carcinoma, according to miR-197-3p expression levels.

\begin{tabular}{|c|c|c|c|c|}
\hline \multirow[b]{2}{*}{ Feature } & \multicolumn{2}{|c|}{ miR-197-3p } & \multirow[b]{2}{*}{$\chi^{2}$ value } & \multirow[b]{2}{*}{ P-value } \\
\hline & $\begin{array}{c}\text { High } \\
(n=99)\end{array}$ & $\begin{array}{c}\text { Low } \\
(n=98)\end{array}$ & & \\
\hline Age in years & & & 0.610 & 0.435 \\
\hline$\geq 55$ & 44 & 49 & & \\
\hline$<55$ & 55 & 49 & & \\
\hline Sex & & & 0.070 & 0.791 \\
\hline Male & 90 & 88 & & \\
\hline Female & 9 & 10 & & \\
\hline $\mathrm{HBsAg}$ & & & 0.134 & 0.714 \\
\hline Positive & 83 & 84 & & \\
\hline Negative & 16 & 14 & & \\
\hline $\mathrm{AFP}, \mu \mathrm{g} / \mathrm{l}$ & & & 56.840 & $<0.001$ \\
\hline Positive & 12 & 63 & & \\
\hline Negative & 87 & 35 & & \\
\hline Cirrhosis & & & 1.845 & 0.174 \\
\hline Present & 47 & 56 & & \\
\hline Absent & 52 & 42 & & \\
\hline Tumour size, cm & & & 6.288 & 0.012 \\
\hline$\geq 5$ & 34 & 51 & & \\
\hline$<5$ & 65 & 47 & & \\
\hline Tumour number & & & 0.063 & $<0.001$ \\
\hline Multiple & 34 & 32 & & \\
\hline Single & 65 & 66 & & \\
\hline Capsule & & & 13.438 & $<0.001$ \\
\hline Present & 65 & 86 & & \\
\hline Absent & 34 & 12 & & \\
\hline Vascular invasion & & & 6.214 & 0.013 \\
\hline Present & 40 & 57 & & \\
\hline Absent & 59 & 41 & & \\
\hline TNM stage & & & 0.412 & 0.521 \\
\hline I-II & 36 & 40 & & \\
\hline III-IV & 63 & 58 & & \\
\hline BCLC stage & & & 0.414 & 0.520 \\
\hline A-B & 35 & 39 & & \\
\hline C-D & 64 & 59 & & \\
\hline
\end{tabular}

The median expression level was used as the cut-off. Low miR-197-3p expression in each of the 98 patients was defined as a value below the 50th percentile. High miR-197-3p expression in each of the 99 patients was defined as a value above the 50th percentile. For analysis of correlation between the expression levels of miR-197-3p and clinical features, Pearson's $\chi^{2}$ tests were used. $\mathrm{P}<0.05$ was considered to indicate a statistically significant difference. miR, microRNA; AFP, $\alpha$-fetoprotein; TNM, tumour node metastasis; BCLC stage, Barcelona Clinic Liver Cancer stage; HBsAg, hepatitis B virus surface antigen.

level $<20 \mu \mathrm{g} / \mathrm{l})$ are generally considered to have a better prognosis $(25,26)$; nevertheless, many of these patients exhibit early recurrence and poor OS. Therefore, a precise biomarker is required to predict the prognosis of AFP-negative patients. Subgroup analysis revealed that among the 122 AFP-negative patients (AFP serum level $<20 \mu \mathrm{g} / \mathrm{l}$ ), the difference in RFS and OS remained between the high- and low-expression groups $(\mathrm{P}=0.0011$ and $\mathrm{P}=0.0013$, respectively; Fig. 2C and $\mathrm{D})$. Further analysis indicated that of the 121 patients with tumour size $<5 \mathrm{~cm}$, the group with low miR-197-3p expression exhibited significantly poorer RFS and OS $(\mathrm{P}<0.001$; Fig. 2E and F, respectively). Univariate analysis indicated that among the clinicopathological characteristics, RFS was associated with the miR-197-3p expression level, presence of the hepatitis B virus surface antigen, tumour size, tumour number, absence of capsule, vascular invasion, TNM stage and BCLC stage, whilst the OS was associated with the miR-197-3p expression level, tumour size, tumour number, absence of capsule, vascular invasion, TNM stage and BCLC stage (Table II). Furthermore, multivariate Cox regression analysis revealed that independent risk factors for HCC recurrence and survival included the miR-197-3p expression level, tumour size, tumour number and vascular invasion, while those for the OS in patients with HCC included the miR-197-3p expression level, tumour size, tumour number, absence of capsule and vascular invasion (Table III). Based on the above results, it may be concluded that the expression level of miR-197-3p may be adopted as an independent factor for predicting the prognosis of HCC.

Inhibitory effects of miR-197-3p on the metastasis and invasion of HCC cells in vitro. To functionally characterise miR-197-3p in HCC, HCCLM3 cells were selected for a gain- of-function and loss-of-function study. To this end, miR-197-3p stably-overexpressing HCC-LM3-Mimic, and stably downregulated HCC-LM3-Inhibitor cells were generated; the difference in the miR-197-3p expression levels was detected via RT-qPCR (Fig. 3A and B). The MTT assay revealed that miR-197-3p did not affect the growth of HCC cells (Fig. 3C and D). In the wound-healing migration assay, microscopic examination at 0 and $24 \mathrm{~h}$ revealed that HCC-LM3-Inhibitor cell migration was significantly enhanced compared with HCC-LM3-NC cell migration $(\mathrm{P}<0.001$; Fig. 4A). By contrast, HCC-LM3-Mimic cell migration was significantly delayed compared with HCC-LM3-NC cell migration and invasiveness $(\mathrm{P}<0.001$; Fig. 4B). The Transwell assay also revealed that the HCC-LM3-Inhibitor cells displayed increased migration and invasiveness, compared with the other cell types, whereas the HCC-LM3-Mimic cells displayed decreased migration and invasiveness compared with the other cell types (Fig. 4C and D). These data indicated that miR-197-3p may promote HCC cell metastasis in vitro.

Direct binding of miR-197-3p to the 3' UTR of ZIK1. To investigate the molecular mechanisms underlying the miR-197-3p-mediated decrease in HCC metastasis, the involvement of miR-197-3p in manipulating EMT was assessed, which is regarded as a key process underlying cell metastasis. It was observed that miR-197-3p exhibited no significant effect on the expression levels of EMT-associated genes including E-cadherin, N-cadherin, and vimentin (Fig. 5). To identify the genes potentially involved in 
A .

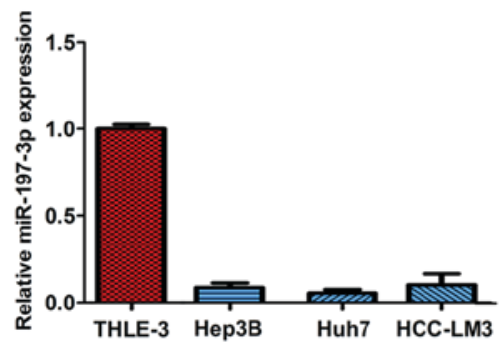

D

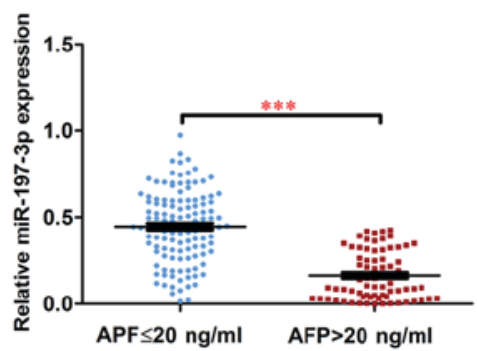

B

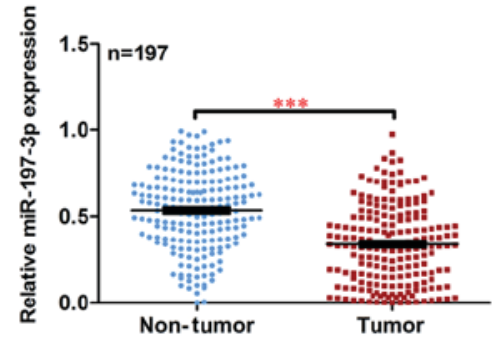

E

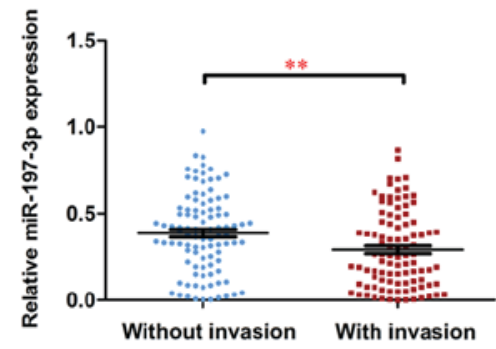

C

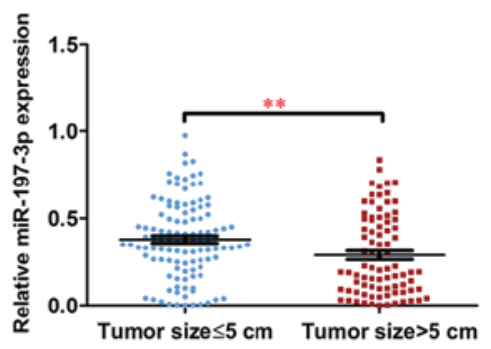

$F$

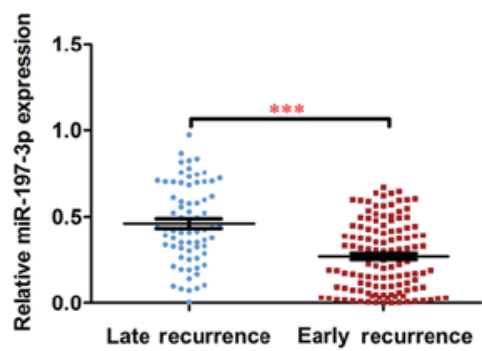

Figure 1. Downregulated expression of miR-197-3p in HCC. (A) miR-197-3p expression levels were examined in various human HCC and hepatocyte THLE-3 cells. (B) miR-197-3p expression levels were compared between HCC tissue samples and the paired adjacent non-tumour tissue samples. U6 was used as an internal control to normalize the expression level of miR-197-3p. (C) miR-197-3p expression levels were examined in larger and smaller HCC tissue samples. (D) miR-197-3p levels were compared between AFP-negative and AFP-positive HCC patients. (E) miR-197-3p expression levels were examined in HCC tissues with and without vascular invasion. (F) miR-197-3p levels were compared between HCC tissues exhibiting late recurrence and HCC tissues exhibiting early recurrence. ${ }^{* *} \mathrm{P}<0.01$ and ${ }^{* * *} \mathrm{P}<0.001$. HCC, hepatocellular carcinoma; miR, microRNA; AFP, $\alpha$-fetoprotein.
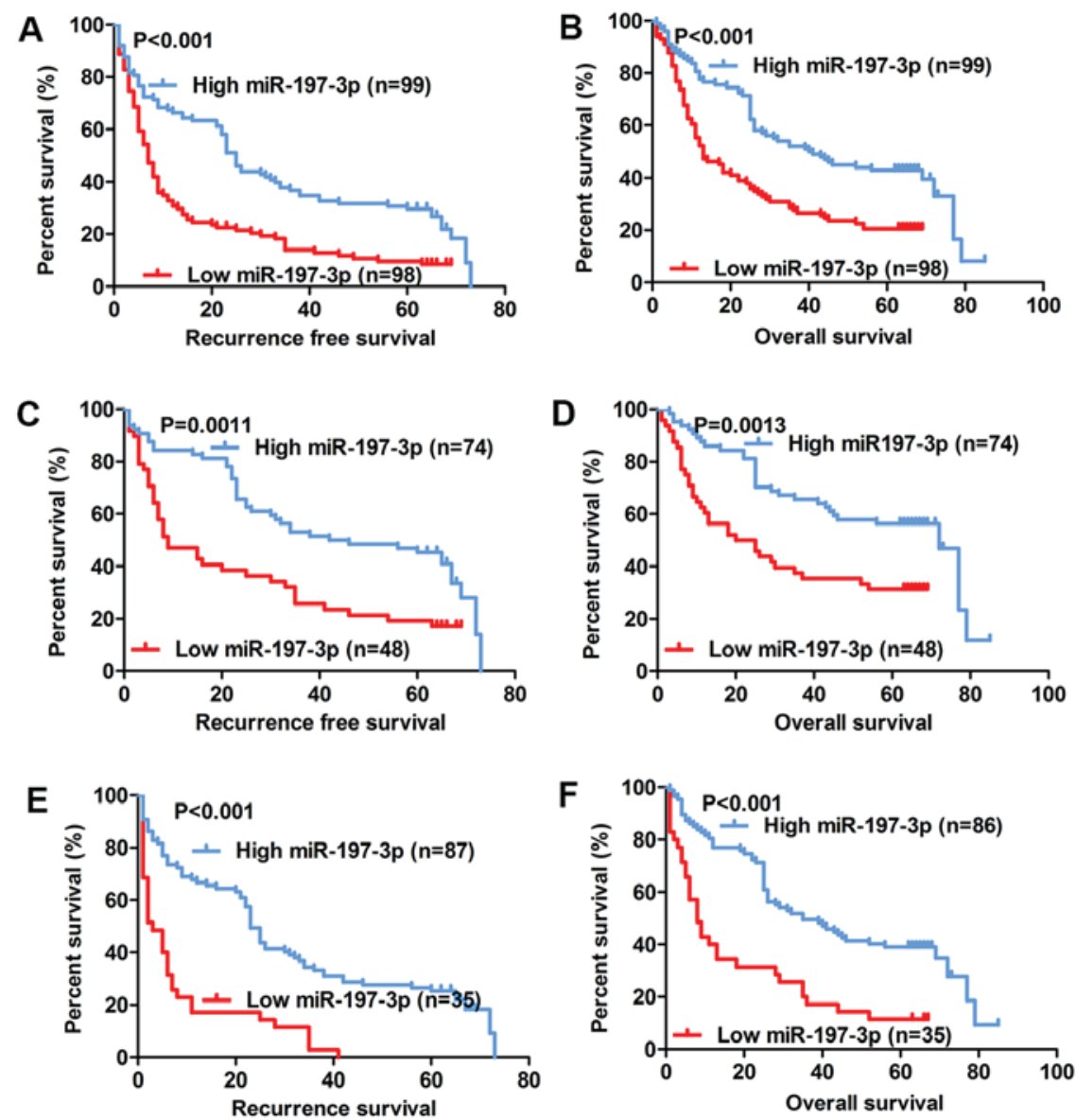

Figure 2. Association between miR-197-3p expression and prognosis of patients with hepatocellular carcinoma. The low-miR-197-3p subgroup (n=98) exhibited a significantly shorter (A) RFS and (B) OS compared with the high-miR-197-3p subgroup ( $n=99$ ). In reference to (C) RFS and (D) OS, the prognostic value of miR-197-3p was observed in $\alpha$-fetoprotein-negative patients: The low-miR-197-3p subgroup ( $\mathrm{n}=48$ ) vs. the high-miR-197-3p subgroup ( $\mathrm{n}=74)$. In reference to (E) RFS and (F) OS, the prognostic value of miR-197-3p was observed in patients with tumour size $<5 \mathrm{~cm}$ : The low-miR-197-3p subgroup (n=35) vs. the high-miR-197-3p subgroup $(\mathrm{n}=87$ ). Statistical significance was assessed via two-sided log-rank tests. $\mathrm{P}<0.05$ was considered to indicate a statistically significant difference. miR, microRNA; RFS, relapse-free survival; OS, Overall survival. 
Table II. Univariable analysis for RFS and OS.

\begin{tabular}{lcccccr}
\hline & \multicolumn{3}{c}{ RFS } & & \multicolumn{2}{c}{ OS } \\
\cline { 2 - 3 } \cline { 7 - 7 } Variable & Hazard ratio & $95 \%$ CI & P-value & & $95 \%$ CI & P-value \\
\hline Age, years $\geq 55$ vs. $<55$ & 0.921 & $0.676-1.254$ & 0.601 & & $0.742-1.451$ & 0.829 \\
Sex, male vs. female & 0.925 & $0.559-1.531$ & 0.763 & & $0.845-3.070$ & 0.147 \\
HBsAg, positive vs. negative & 1.479 & $0.933-2.344$ & 0.096 & & $0.659-1.675$ & 0.836 \\
AFP, $\mu$ g/l, $\geq 20$ vs. $<20$ & 0.949 & $0.689-1.307$ & 0.747 & & $0.705-1.411$ & 0.988 \\
Cirrhosis, present vs. absent & 0.827 & $0.607-1.126$ & 0.228 & & $0.606-1.185$ & 0.335 \\
Tumour diameter, cm $\geq 5$ vs. $<5$ & 3.451 & $2.460-4.842$ & $<0.001$ & & $1.754-3.495$ & $<0.001$ \\
Tumour number multiple vs. solitary & 2.934 & $2.119-4.087$ & $<0.001$ & & $1.699-3.375$ & $<0.001$ \\
Capsule absent vs. present & 1.671 & $1.143-2.444$ & 0.008 & & $1.075-2.501$ & 0.022 \\
Vascular invasion present vs. absent & 3.602 & $2.578-5.033$ & $<0.001$ & & $2.526-5.229$ & $<0.001$ \\
TNM stage III and IV vs. I and II & 3.039 & $2.189-4.220$ & $<0.001$ & & $1.771-3.518$ & $<0.001$ \\
BCLC stage C and D vs. A and B & 3.129 & $2.250-4.352$ & $<0.001$ & & $1.755-3.486$ & $<0.001$ \\
miR-197-3p expression low vs. high & 1.940 & $1.418-2.656$ & $<0.001$ & & $1.388-2.759$ & $<0.001$ \\
\hline
\end{tabular}

For analysis of correlation Pearson's $\chi^{2}$ tests were used. $\mathrm{P}<0.05$ was considered to indicate a statistically significant difference. RFS, relapse-free survival; miR, microRNA; antigen; AFP, $\alpha$-fetoprotein; TNM, tumour node metastasis; BCLC stage, Barcelona Clinic Liver Cancer stage; HBsAg, hepatitis B virus surface antigen; CI, confidence interval.

Table III. Multivariable analysis of RFS and OS in patients with hepatocellular carcinoma.

\begin{tabular}{|c|c|c|c|c|c|c|c|c|}
\hline \multirow{3}{*}{$\begin{array}{l}\text { Variable } \\
\text { Tumour diameter } \mathrm{cm}, \geq 5 \text { vs. }<5\end{array}$} & \multicolumn{4}{|c|}{ RFS } & \multicolumn{4}{|c|}{ OS } \\
\hline & \multirow{2}{*}{$\begin{array}{l}\text { P-value } \\
<0.001\end{array}$} & \multirow{2}{*}{$\frac{\mathrm{HR}}{2.286}$} & \multicolumn{2}{|c|}{$95 \% \mathrm{CI}$} & \multirow{2}{*}{$\frac{\text { P-value }}{0.053}$} & \multirow{2}{*}{$\frac{\mathrm{HR}}{1.466}$} & \multicolumn{2}{|c|}{$95 \% \mathrm{CI}$} \\
\hline & & & 1.580 & 3.306 & & & 0.995 & 2.161 \\
\hline Tumour number multiple vs. solitary & 0.001 & 1.877 & 1.317 & 2.676 & 0.001 & 1.874 & 1.275 & 2.753 \\
\hline Vascular invasion present vs. absent & $<0.001$ & 2.636 & 1.845 & 3.766 & $<0.001$ & 2.770 & 1.887 & 4.065 \\
\hline miR-197-3p low vs. high & 0.029 & 1.448 & 1.039 & 2.018 & 0.077 & 1.386 & 0.965 & 1.992 \\
\hline Capsule absent vs. present & & & & & 0.082 & 1.476 & 0.952 & 2.288 \\
\hline
\end{tabular}

For analysis of correlation Pearson's $\chi^{2}$ tests were used. $\mathrm{P}<0.05$ was considered to indicate a statistically significant difference. RFS, relapse-free survival; OS, overall survival; miR, microRNA; HR, hazard ratio; CI, confidence interval.

enhancing miR-197-3p expression in HCC cell metastasis, TargetScan was used to predict the genes that miR-197-3p may target. A putative miR-197-3p-binding site was identified within the 3'UTR of ZIK1 (Fig. 6A), and a luciferase reporter assay was used to validate whether ZIK1 was a direct target of miR-197-3p. wild-type (WT) and mutant (MUT) versions of the ZIK1 3' UTR, the latter containing site-directed mutations in the putative miR-197-3p target sites, were cloned into reporter plasmids. The miR-197-3p overexpression markedly suppressed luciferase activity from the wild-type, though not the mutant reporter. This suggested that the 3' UTR of ZIK1 was targeted by miR-197-3p, and that the point mutations in this sequence abolished this effect in HCCLM3 (Fig. 6B). In addition, the protein expression levels of ZIK1 were markedly reduced following miR-197-3p overexpression, while the protein expression level of ZIK1 was increased following miR-197-3p knockdown in HCCLM3 cells (Fig. 6D). By contrast, no significant differences were observed in the ZIK1
mRNA expression levels (Fig. 6C). These results indicated that miR-197-3p may suppress ZIK1 expression through translational repression.

To determine whether the ZIK1 gene is required for the effect of miR-197-3p on HCC cell metastasis, ectopic overexpression of ZIK1 was performed to conduct functional studies in HCCLM3 cells (Fig. 6E). The migration and invasion capacities in HCC cells overexpressing ZIK1 were significantly inhibited, while overexpression of ZIK1 abolished the effect of miR-197-3p on migration and invasion of HCC cells (Fig. 6E). Therefore, overexpression of ZIK1 abolished the effects of miR-197-3p on specific HCC cell phenotypes.

\section{Discussion}

Although numerous growth factors, oncogenes and tumour suppressor genes have been associated with hepatocarcinogenesis $(27,28)$, the molecular mechanisms and the pathogenic 
A

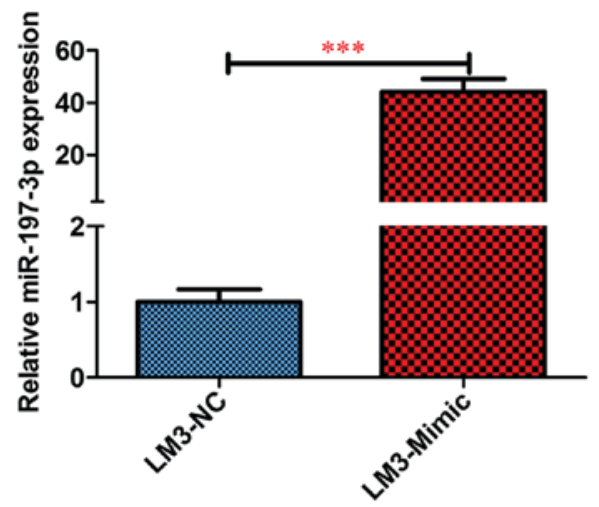

C

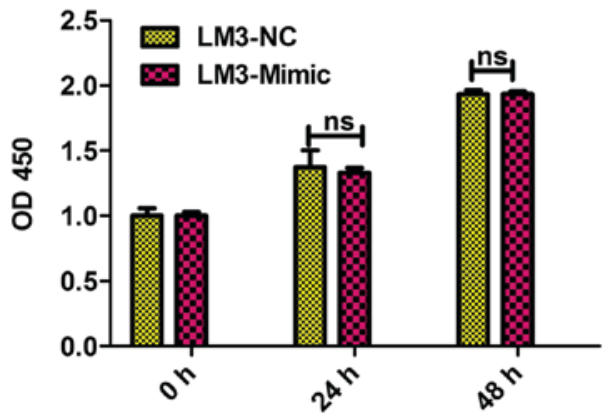

B

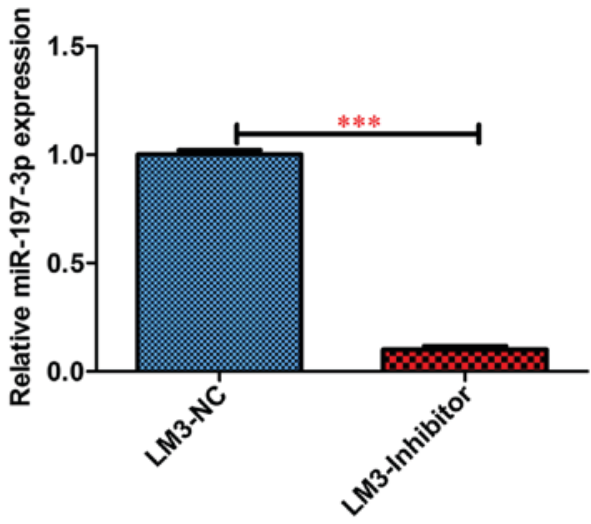

D

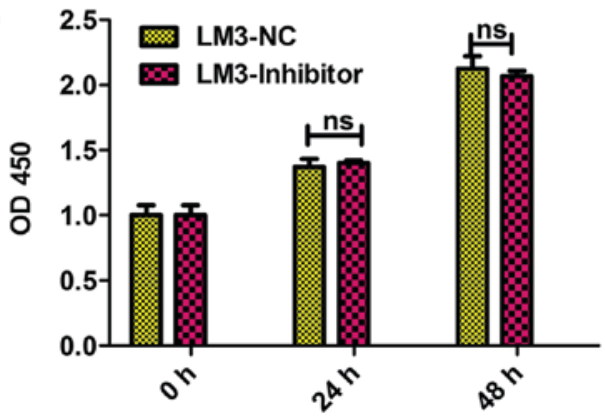

Figure 3. Effect of miR-197-3p on the growth of hepatocellular carcinoma cells. (A) miR-197-3p expression levels were significantly increased in LM3-mimic cells compared with those in LM3-NC cells. (B) miR-197-3p expression levels were significantly reduced in LM3-inhibitor cells compared with those in LM3-NC cells. The growth curves of the (C) LM3-Mimic, (D) LM3-Inhibitor and their respective controls. ${ }^{* * *} \mathrm{P}<0.001$. miR, microRNA; NC, negative control; OD, optical density.
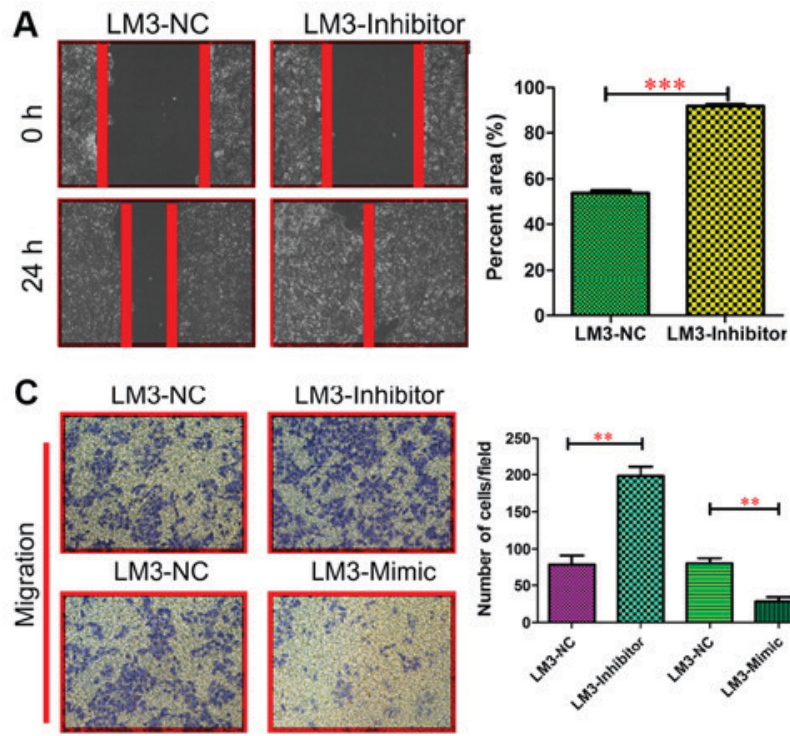

LM3-Inhibitor
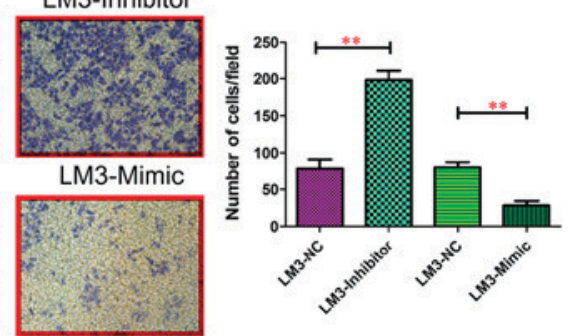
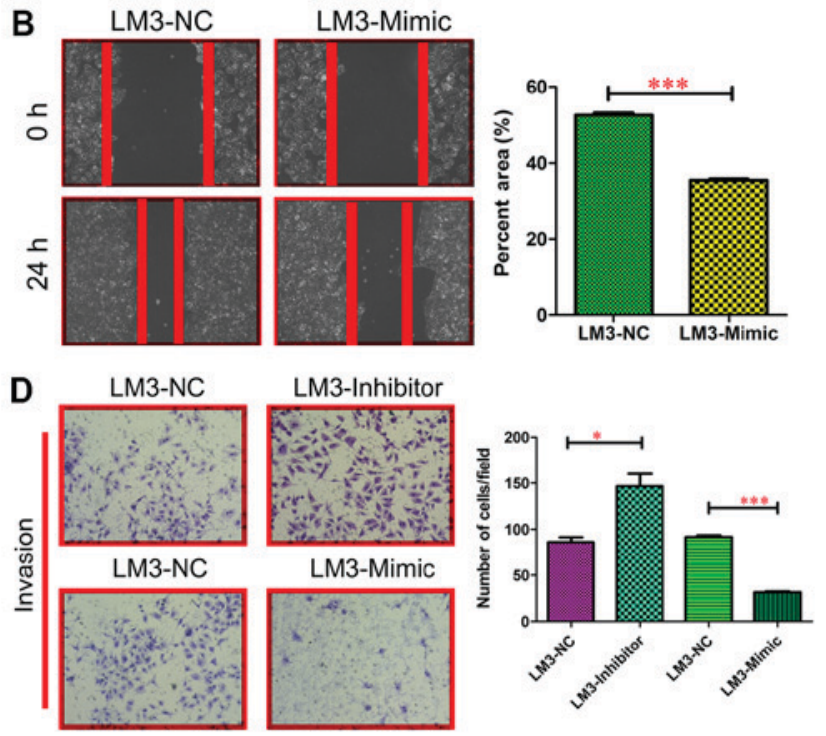

Figure 4. Inhibitory effects of miR-197-3p in the metastasis and invasion of HCC cells in vitro. Wound-healing in (A) LM3-inhibitor and (B) LM3-mimic cells, compared with the LM3-NC cell control. (C) Transwell migration assays (D) Matrigel invasion assays in each HCC cell line. Cells were counted in three randomized fields at a magnification of $\mathrm{x} 100$. Error bars represent the mean \pm standard deviation of triplicate assays. ${ }^{*} \mathrm{P}<0.05,{ }^{* *} \mathrm{P}<0.01$ and ${ }^{* * *} \mathrm{P}<0.001$. $\mathrm{HCC}$, hepatocellular carcinoma; miR, microRNA; NC, negative control.

biology of HCC remain unclear. In addition to reports that miRNAs participates in the regulation of almost every cellular process investigated to date, there have been reports that they are involved in the pathogenesis of $\operatorname{HCC}(29,30)$. miR-197-3p was recognized as an oncogene in prostate cancer (31); however, the characterisation of miR-197-3p in $\mathrm{HCC}$ and its association with cancer progression and development remain largely unknown. In the present study, miR-197-3p was downregulated in HCC tumour tissues and HCC cell lines. miR-197-3p downregulation correlated with higher AFP levels ( $\geq 20 \mu \mathrm{g} / \mathrm{l})$, larger tumour sizes $(\geq 5 \mathrm{~cm})$, multiple tumours $(n \geq 2)$, absence of capsule and vascular 

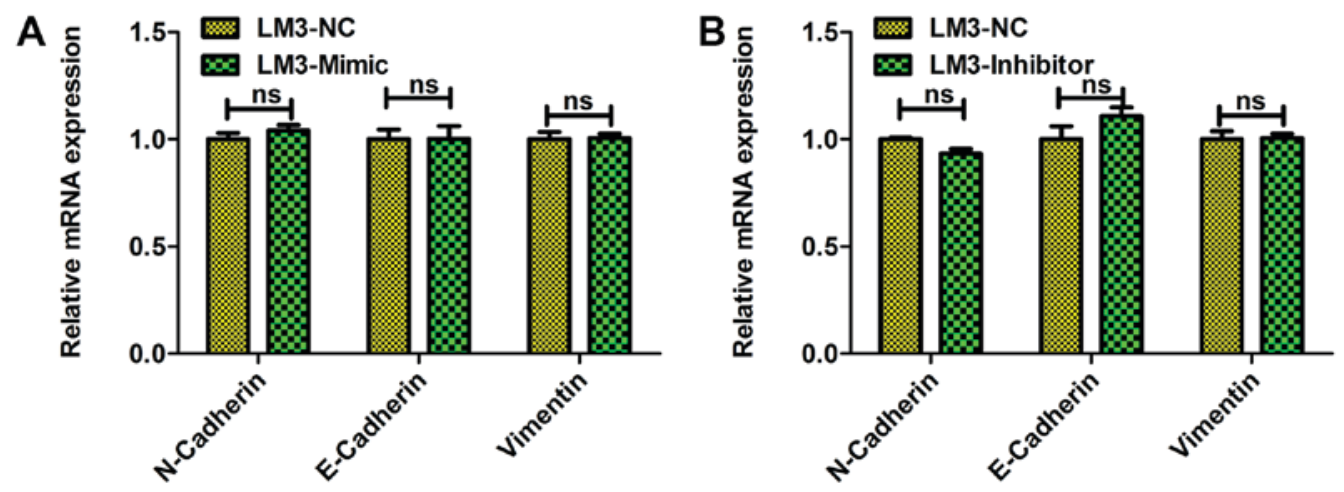

Figure 5. Effects of miR-197-3p on the expression levels of epithelial mesenchymal transition-associated genes. E-cadherin, N-cadherin, and vimentin mRNA expression levels were compared by RT-qPCR in (A) LM3-inhibitor and (B) LM3-mimic cells, compared with the LM3-NC cell control. miR, microRNA; ns, not significant; NC, negative control.

A

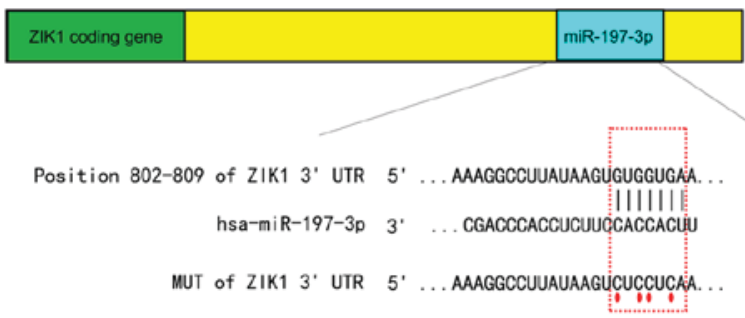

B

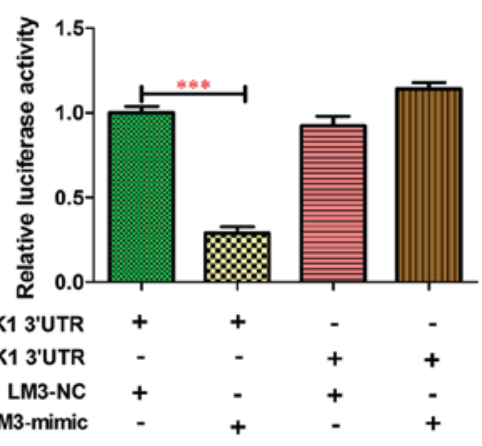

C

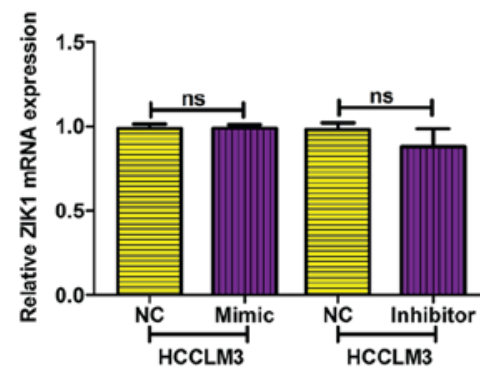

E

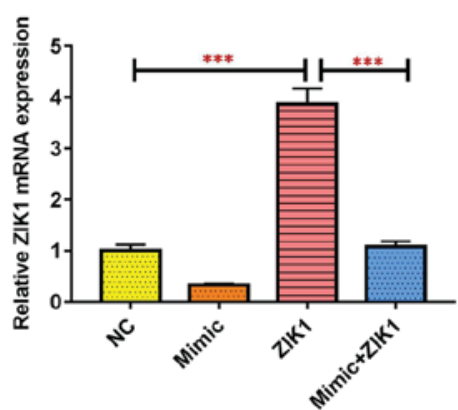

D
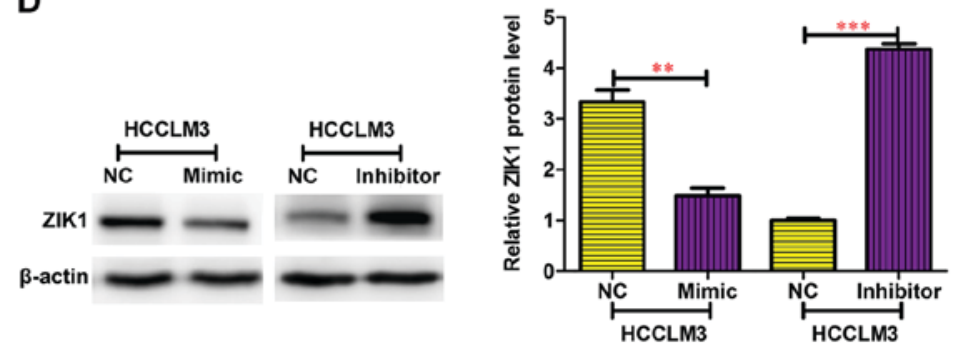

$\mathbf{F}$
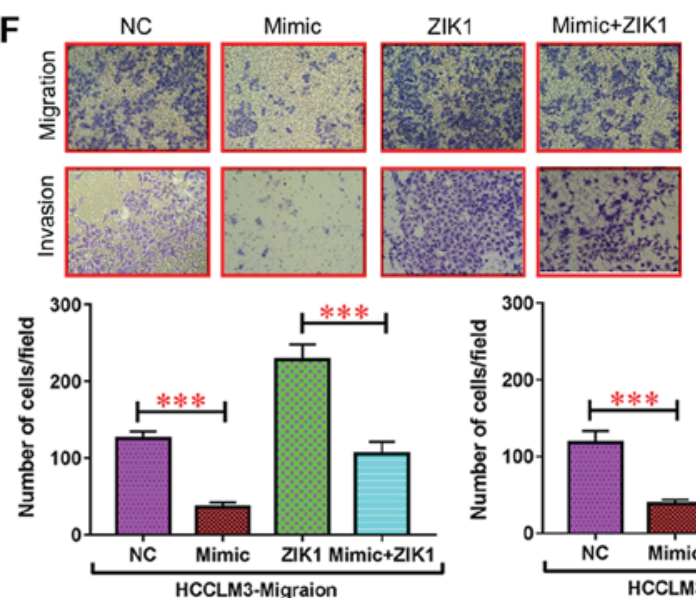

Figure 6. Direct binding of miR-197-3p to the 3'UTR of ZIK1. (A) The putative miR-197-3p-binding sites on the ZIK1 3'UTR and the mutated miR-197-3p-binding sites generated by site-directed mutagenesis. (B) In HCCLM3 cells, the suppression of luciferase activity was only apparent when miR-197-3p was partnered with wild-type ZIK1 3'UTR. (C) ZIK1 mRNA expression in response to miR-197-3p mimic and miR-197-3p inhibitor in HCCLM3 cells. (D) Western blot analysis of ZIK1 protein expression following transfection in HCCLM3 cells. (E) mRNA expression level of ZIK1 in HCCLM3 cells overexpressing ZIK1 and co-transfected with an miR-197-3p mimic. (F) The migratory properties of the cells were analysed using the Transwell migration assay. The results are plotted as the average number of migrated cells from six random microscopic fields (magnification, x3.9), and the invasive properties of the cells were analysed via the invasion assay using BioCoat Matrigel invasion chambers. The results are presented as the average number of invasive cells from six random microscopic fields. ${ }^{* *} \mathrm{P}<0.01$ and ${ }^{* * *} \mathrm{P}<0.001$. UTR, untranslated region; WT, wild-type; MUT, mutant; ZIK1, zinc finger protein interacting with $\mathrm{K}$ protein 1 ; NC, negative control; ns, not significant. 
invasion. AFP is a well-established diagnostic biomarker in the screening of HCC (32-35); an online literature search revealed that the positive rate of AFP in HCC patients was reportedly between 50 (36) and 53\% (37). which declines to $47 \%$ for patients with small hepatocellular carcinoma (38). In the present study, $61 \%$ of the patients were in the early stages of HCC (TNM stage I or II), and many had a small tumour volume; therefore, the incidence of AFP appeared to be lower compared with that in other reports. The correlation between the expression of miR-197-3p and AFP levels indicated that miR-197-3p may be a potential biomarker in HCC diagnosis. Additionally, its association with tumour number and size, presence of capsule and vascular invasion suggests a potential role of miR-197-3p in HCC.

MicroRNAs can function as tumour suppressors or oncogenes by targeting their respectively associated genes $(39,40)$. miR-197-3p targets that may contribute to miR-197-3p-mediated inhibition of cell metastasis in HCC were further investigated. Using TargetScan bioinformatics, the ZIK1 gene was potentially identified as a direct target for miR-197-3p. ZIK1 was first proposed as a transcriptional repressor that binds to the nuclear ribonucleoprotein particle K protein (41), and was subsequently identified by methylation sensitive representational difference analysis as being hypermethylated in the intestinal metaplasia of the stomach (42). In support of this finding, Mihara et al (43) reported that ZIK1 is hypermethylated in $100 \%$ of human gastric intestinal metaplasia samples, which suggests that epigenetic silencing of ZIK1 may contribute to the pathogenesis of gastric neoplasia. The expression levels of ZIK1 are also reportedly associated with the progression of renal cell carcinoma (44), diffuse large B-cell lymphoma (45), oesophageal cancer (46) and colorectal cancer $(47,48)$; Borinstein et al (48) assessed the role of aberrant DNA methylation in the azoxymethane rodent model of colon cancer and revealed that ZIK1 displayed aberrant DNA methylation in the tumours that were absent or present at a low frequency in the normal colon, which suggested that ZIK1 may serve an important role in the transformation of gastrointestinal mucosal cells Moreover, ZIK1 was significantly upregulated in cluster of differentiation (CD) $133^{+}$colorectal carcinoma cells compared with their CD133- counterpart. CD133 expression, which identified a considerable population of tumour-initiating cells in colorectal cancer, reportedly correlated with tumour metastasis (47). The level of ZIK1 expression was also higher in renal cell carcinoma compared with the normal kidney (44). However, despite the fact that it is a zinc finger protein and a potential transcription factor, little is known of its function. The present study verified that miR-197-3p directly targets ZIK1 by interacting with its 3'UTR, indicating that miR-197-3p may suppress HCC cell metastasis, in part by targeting ZIK1.

In conclusion, the present study indicated that miR-197-3p expression was frequently decreased in HCC tumour tissues, and it may serve as a prognostic biomarker in patients with HCC. The results indicated that miR-197-3p may inhibit HCC cell metastasis by directly suppressing the expression of ZIK1, which not only sheds new light on HCC progression and metastasis, but provides a potential target for cancer prevention and treatment.

\section{Acknowledgements}

Not applicable.

\section{Funding}

The present study was supported by the National Key Basic Research Program of China, (grant no. 2014CB542102); The Shanghai Health and Family Planning Commission Foundation (grant no. 20164Y0189); The National Human Genetic Resources Sharing Service Platform (grant no. 2005DKA21300); The Science Fund for Creative Research Groups, NSFC, China (grant no. 81521091); and The State Key Infection Disease Project of China (grant no. 2017ZX10203208).

\section{Availability of data and materials}

The datasets used and/or analysed during the present study are available from the corresponding author on reasonable request.

\section{Authors' contributions}

WPZ and YY conceived the study and designed the experiments. ZGW and MCW provided the experimental materials. JSN, HZ, ZPH, YLO and YPT performed the experiments with the help of YGH. JSN and HZ performed the data analysis. ZPH and YPT wrote the manuscript. All authors contributed to the interpretation and discussion of the results and reviewed the manuscript.

\section{Ethics approval and consent to participate}

The present study was approved by the Institutional Review Board of the Eastern Hepatobiliary Surgery Hospital. All patients gave written informed consent to participate in the study and the data were anonymised.

\section{Patient consent for publication}

Not applicable.

\section{Competing interests}

The authors declare that they have no competing interests.

\section{References}

1. Ye JZ, Wang YY, Bai T, Chen J, Xiang BD, Wu FX and Li LQ: Surgical resection for hepatocellular carcinoma with portal vein tumor thrombus in the Asia-Pacific region beyond the Barcelona Clinic Liver Cancer treatment algorithms: A review and update. Oncotarget 8: 93258-93278, 2017.

2. Orcutt ST and Anaya DA: Liver resection and surgical strategies for management of primary liver cancer. Cancer Control 25: $1073274817744621,2018$.

3. Ren FH, Yang H, He RQ, Lu JN, Lin XG, Liang HW, Dang YW, Feng ZB, Chen G and Luo DZ: Analysis of microarrays of miR-34a and its identification of prospective target gene signature in hepatocellular carcinoma. BMC Cancer 18: 12, 2018.

4. Geng M, Xin X, Bi LQ, Zhou LT and Liu XH: Molecular mechanism of hepatitis $B$ virus $X$ protein function in hepatocarcinogenesis. World J Gastroenterol 21: 10732-10738, 2015.

5. Novikova MV, Khromova NV and Kopnin PB: Components of the hepatocellular carcinoma microenvironment and their role in tumor progression. Biochemistry (Mosc) 82: 861-873, 2017. 
6. Yoo S, Wang W, Wang Q, Fiel MI, Lee E, Hiotis SP and Zhu J: A pilot systematic genomic comparison of recurrence risks of hepatitis B virus-associated hepatocellular carcinoma with lowand high-degree liver fibrosis. BMC Med 15: 214, 2017.

7. Wang $G$, Fang $X$, Han $M$, Wang $X$ and Huang Q: MicroRNA-493-5p promotes apoptosis and suppresses proliferation and invasion in liver cancer cells by targeting VAMP2. Int J Mol Med 41: 1740-1748, 2018.

8. Lin H, Ewing LE, Koturbash I, Gurley BJ and Miousse IR: MicroRNAs as biomarkers for liver injury: Current knowledge, challenges and future prospects. Food Chem Toxicol 110: 229-239, 2017.

9. Loosen SH, Schueller F, Trautwein C, Roy S and Roderburg C: Role of circulating microRNAs in liver diseases. World $\mathrm{J}$ Hepatol 9: 586-594, 2017.

10. Ashmawy AM, Elgeshy KM, Abdel Salam ET, Ghareeb M, Kobaisi MH, Amin HAA, Sharawy SK and Abdel Wahab AHA: Crosstalk between liver-related microRNAs and Wnt/ $\beta$-catenin pathway in hepatocellular carcinoma patients. Arab J Gastroenterol 18: 144-150, 2017.

11. Singaravelu R, Quan C, Powdrill MH, Shaw TA, Srinivasan P, Lyn RK, Alonzi RC, Jones DM, Filip R, Russell RS and Pezacki JP: MicroRNA-7 mediates cross-talk between metabolic signaling pathways in the liver. Sci Rep 8: 361, 2018

12. Zhou SJ, Liu FY, Zhang AH, Liang HF, Wang Y, Ma R, Jiang YH and Sun NF: MicroRNA-199b-5p attenuates TGF- $\beta 1$-induced epithelial-mesenchymal transition in hepatocellular carcinoma. Br J Cancer 117: 233-244, 2017.

13. Hu D, Hu Y, Xu W, Yu H, Yang N, Ni S and Fu R: miR-203 inhibits the expression of collagen-related genes and the proliferation of hepatic stellate cells through a SMAD3-dependent mechanism. Mol Med Rep 16: 1248-1254, 2017.

14. Riazalhosseini B, Mohamed R, Apalasamy YD, Langmia IM and Mohamed Z: Circulating microRNA as a marker for predicting liver disease progression in patients with chronic hepatitis B. Rev Soc Bras Med Trop 50: 161-166, 2017.

15. Wang S, Wang JQ and Lv XW: Exosomal miRNAs as biomarkers in the diagnosis of liver disease. Biomark Med 11: 491-501, 2017.

16. Slaby O, Laga $R$ and Sedlacek O: Therapeutic targeting of non-coding RNAs in cancer. Biochem J 474: 4219-4251, 2017.

17. Vettukattil JJ: Is the hepatic factor a miRNA that maintains the integrity of pulmonary microvasculature by inhibiting the vascular endothelial growth factor? Curr Cardiol Rev 13: 244-250, 2017.

18. Wang YY, Wu ZY, Wang GC, Liu K, Niu XB, Gu S and Meng JS: LINC00312 inhibits the migration and invasion of bladder cancer cells by targeting miR-197-3p. Tumor Biol 37: 14553-14563, 2016.

19. Liu K, Huang W, Yan DQ, Luo Q and Min X: Overexpression of long intergenic noncoding RNA LINC00312 inhibits the invasion and migration of thyroid cancer cells by down-regulating microRNA-197-3p. Biosci Rep 37: pii: BSR20170109, 2017.

20. Pirisi M, Leutner M, Pinato DJ, Avellini C, Carsana L, Toniutto P, Fabris $C$ and Boldorini R: Reliability and reproducibility of the edmondson grading of hepatocellular carcinoma using paired core biopsy and surgical resection specimens. Arch Pathol Lab Med 134: 1818-1822, 2010

21. Chansky K, Sculier JP, Crowley JJ, Giroux D, Van Meerbeeck J and Goldstraw P; International Staging Committee and Participating Institutions: The international association for the study of lung cancer staging project: Prognostic factors and pathologic TNM stage in surgically managed non-small cell lung cancer. J Thorac Oncol 4: 792-801, 2009.

22. Zhong JH, Xiang BD, Gong WF, Ke Y, Mo QG, Ma L, Liu X and Li LQ: Comparison of long-term survival of patients with BCLC stage B hepatocellular carcinoma after liver resection or transarterial chemoembolization. PLoS One 8: e68193, 2013

23. Livak KJ and Schmittgen TD: Analysis of relative gene expression data using real-time quantitative PCR and the 2(-Delta Delta C(T)) method. Methods 25: 402-408, 2001.

24. Wang RY, Chen L, Chen HY, Hu L, Li L, Sun HY, Jiang F, Zhao J, Liu GM, Tang J, et al: MUC15 inhibits dimerization of EGFR and PI3K-AKT signaling and is associated with aggressive hepatocellular carcinomas in patients. Gastroenterology 145 : 1436-1448.e1-e12, 2013

25. Shiraki K, Takase K, Tameda Y, Hamada M, Kosaka Y and Nakano T: A clinical study of lectin-reactive alpha-fetoprotein as an early indicator of hepatocellular carcinoma in the follow-up of cirrhotic patients. Hepatology 22: 802-807, 1995.

26. Li D, Mallory T and Satomura S: AFP-L3: A new generation of tumor marker for hepatocellular carcinoma. Clin Chim Acta 313: $15-19,2001$.
27. Lv X, Li J and Yang B: Clinical effects of miR-101 on prognosis of hepatocellular carcinoma and carcinogenic mechanism of anti-miR-101. Oncol Rep 36: 2184-2192, 2016.

28. Murakami Y, Kubo S, Tamori A, Itami S, Kawamura E, Iwaisako K, Ikeda K, Kawada N, Ochiya T and Taguchi YH: Comprehensive analysis of transcriptome and metabolome analysis in intrahepatic cholangiocarcinoma and hepatocellular carcinoma. Sci Rep 5: 16294, 2015.

29. Qadir MI and Rizvi SZ: miRNA in hepatocellular carcinoma: Pathogenesis and therapeutic approaches. Crit Rev Eukaryot Gene Expr 27: 355-361, 2017.

30. Almas I, Afzal S, Idrees M, Ashraf MU, Amin I, Shahid M, Zahid K and Zahid S: Role of circulatory microRNAs in the pathogenesis of hepatitis C virus. Virusdisease 28: 360-367, 2017.

31. Daniel R, Wu Q, Williams V, Clark G, Guruli G and Zehner Z: A panel of MicroRNAs as diagnostic biomarkers for the identification of prostate cancer. Int J Mol Sci 18: pii: E1281, 2017.

32. Tayob N, Richardson P, White DL, Yu X, Davila JA, Kanwal F, Feng Z and El-Serag HB: Evaluating screening approaches for hepatocellular carcinoma in a cohort of $\mathrm{HCV}$ related cirrhosis patients from the Veteran's Affairs Health Care System. BMC Med Res Methodol 18: 1, 2018.

33. Ricco G, Cavallone D, Cosma C, Caviglia GP, Oliveri F, Biasiolo A, Abate ML, Plebani M, Smedile A, Bonino F, et al: Impact of etiology of chronic liver disease on hepatocellular carcinoma biomarkers. Cancer Biomark 21: 603-612, 2018.

34. Luma HN, Eloumou SAFB, Okalla C, Donfack-Sontsa O, Koumitana R, Malongue A, Nko'Ayissi GB and Noah DN: Prevalence and characteristics of hepatitis delta virus infection in a tertiary hospital setting in cameroon. J Clin Exp Hepatol 7: 334-339, 2017.

35. Xu WF, Fei YM, Zhou JK, Shen HJ, Chen XF, Lv QQ and Ding YY: Significance of serum golgi protein 73 (GP73), alpha-fetoprotein (AFP) and lectin-reactive alpha-fetoprotein (AFP-L3) expresssion in primary hepatic carcinoma. Zhonghua Shi Yan He Lin Chuang Bing Du Xue Za Zhi 25: 286-288, 2011 (In Chinese).

36. Kamiyama T, Takahashi M, Nakagawa T, Nakanishi $\mathrm{K}$, Kamachi H, Suzuki T, Shimamura T, Taniguchi M, Ozaki M, Matsushita M, et al: AFP mRNA detected in bone marrow by real-time quantitative RT-PCR analysis predicts survival and recurrence after curative hepatectomy for hepatocellular carcinoma. Ann Surg 244: 451-463, 2006.

37. Hartmann JT, Rick O, Oechsle K, Kuczyk M, Gauler T, Schöffski P, Schleicher J, Mayer F, Teichmann R, Kanz L and Bokemeyer C: Role of postchemotherapy surgery in the management of patients with liver metastases from germ cell tumors. Ann Surg 242: 260-266, 2005.

38. Huang GT, Lee PH, Tsang YM, Lai MY, Yang PM, Hu RH, Chen PJ, Kao JH, Sheu JC, Lee CZ and Chen DS: Percutaneous ethanol injection versus surgical resection for the treatment of small hepatocellular carcinoma: A prospective study. Ann Surg 242: 36-42, 2005.

39. Liu Y, Yang Z, Du F, Yang Q, Hou J, Yan X, Geng Y, Zhao Y and Wang H: Molecular mechanisms of pathogenesis in hepatocellular carcinoma revealed by RNA-sequencing. Mol Med Rep 16: 6674-6682, 2017.

40. Morimoto A, Kannari M, Tsuchida Y, Sasaki S, Saito C, Matsuta T, Maeda T, Akiyama M, Nakamura T, Sakaguchi M et al: An HNF4 $\alpha$-microRNA-194/192 signaling axis maintains hepatic cell function. J Biol Chem 292: 10574-10585, 2017.

41. Denisenko ON, O'Neill B, Ostrowski J, Van Seuningen I and Bomsztyk K: Zik1, a transcriptional repressor that interacts with the heterogeneous nuclear ribonucleoprotein particle $\mathrm{K}$ protein. J Biol Chem 271: 27701-27706, 1996.

42. Ota T, Suzuki Y, Nishikawa T, Otsuki T, Sugiyama T, Irie R, Wakamatsu A, Hayashi K, Sato H, Nagai K, et al: Complete sequencing and characterization of 21,243 full-length human cDNAs. Nat Genet 36: 40-45, 2004.

43. Mihara M, Yoshida Y, Tsukamoto T, Inada K, Nakanishi Y, Yagi Y, Imai K, Sugimura T, Tatematsu M and Ushijima T: Methylation of multiple genes in gastric glands with intestinal metaplasia: A disorder with polyclonal origins. Am J Pathol 169: 1643-1651, 2006.

44. Zhao Q, Kun D, Hong B, Deng X, Guo S, Tang X, Yang Y, Gong K, Li Q, Ye L, et al: Identification of novel proteins interacting with vascular endothelial growth inhibitor 174 in renal cell carcinoma. Anticancer Res 37: 4379-4388, 2017. 
45. Liu P, Jiang $\mathrm{W}$, Zhao $\mathrm{J}$ and Zhang $\mathrm{H}$ : Integrated analysis of genome-wide gene expression and DNA methylation microarray of diffuse large B-cell lymphoma with TET mutations. Mol Med Rep 16: 3777-3782, 2017.

46. Oka D, Yamashita S, Tomioka T, Nakanishi Y, Kato H, Kaminishi $\mathrm{M}$ and Ushijima T: The presence of aberrant DNA methylation in noncancerous esophageal mucosae in association with smoking history: A target for risk diagnosis and prevention of esophageal cancers. Cancer 115: 3412-3426, 2009.

47. Kim ST, Sohn I, Do IG, Jang J, Kim SH, Jung IH, Park JO, Park YS, Talasaz A, Lee J and Kim HC: Transcriptome analysis of CD133-positive stem cells and prognostic value of survivin in colorectal cancer. Cancer Genomics Proteomics 11: 259-266, 2014
48. Borinstein SC, Conerly M, Dzieciatkowski S, Biswas S, Washington MK, Trobridge P, Henikoff S and Grady WM: Aberrant DNA methylation occurs in colon neoplasms arising in the azoxymethane colon cancer model. Mol Carcinog 49: 94-103, 2010.

This work is licensed under a Creative Commons Attribution-NonCommercial-NoDerivatives 4.0 International (CC BY-NC-ND 4.0) License. 